\title{
A CLINICO-PATHOLOGICAL REPORT ON UNUSUAL CASES OF CHRONIC ENCEPHALITIS
}

\author{
BY \\ WILLIAM R. ROSANOFF * \\ From the Teaching and Research Laboratory, Maudsley Hospital, London
}

(Received 30Th November, 1946)

THE purpose of this paper is to describe three unusual cases of encephalitis which do not fit easily into the recognized types. They have in common an insidious onset, a subacute or chronic course, and a rather diffuse spread of the lesions throughout grey and white matter. It is not suggested that these common features necessarily imply any ætiological relationship between the cases, each of which has its own clinico-pathological prufile.

\section{Case Histories}

\section{CASE 1}

A girl, aged 6 years, was admitted to the Leavesden Hospital, Hertfordshire, on Feb. 21, 1940 and died on July 2, 1940.

History Before Admission.-The child was thought to be perfectly well on Sept. 1, 1939, when she was evacuated from London because of the expected bombing. A month thereafter (five months before admission to hospital) she became lost in the streets and later seemed to have no recollection of having been lost. When her mother visited her a week later the child appeared not to recognize her. She was noted to be "difficult to handle" in school, and at the request of the teacher was removed. About December it was noted that she could not hold things in her hands. Seven weeks before admission she started falling frequently, first to the left, then forward. This grew progressively worse until at the time of admission she could hardly walk two or three steps without falling. Apparently her mental condition had deteriorated steadily, since at the time of admission she did not seem to recognize her parents and could not feed herself.

The family and past histories were irrelevant.

Examination.-The patient lay quietly in bed propped on pillows, head dropped on the left shoulder, arms flexed over the chest. She was pale and thin, whined when touched, and tended to bite at anything placed near her mouth. Her temperature was $100^{\circ} \mathrm{F}$. General physical examination revealed no other positive findings. Neuro-

\footnotetext{
* S. A. Surgeon, U.S. Public Health Service.
}

logical examination showed that the pupils were dilated and equal, and reacted normally to light. There was slight blurring of the nasal side of the discs. The eyes deviated to the left, but voluntary movements were normal. No other cranial nerve abnormalities were noted. There was no definite weakness of the arms or legs. There was thought to be increased tonus in the legs. The deep reflexes were equal and active. The abdominal reflexes were present in the upper quadrants but not in the lower.

Laboratory studies revealed that the urine was normal ; there were $5 \cdot 1$ million red blood cells per c.mm. of blood ; the hæmoglobin was $84 \%$; and the white blood count was 7,600 , with $73 \%$ neutrophils, $24 \%$ lymphocytes, $2 \%$ monocytes, $1 \%$ eosinophils.

Cerebrospinal fluid obtained from the ventricles on Feb. 17 contained one cell per c.mm. Cultures were negative. The fluid was anticomplementary.

Course.-The patient went slowly but steadily down hill. For the most part her temperature was between $98^{\circ}$ and $100^{\circ}$ F.; but on two occasions, each lasting three or four days, it rose daily to $102^{\circ} \mathrm{F}$. After Feb. 24 the abdominal reflexes were absent. Marked tremor of the arms was noted on Feb. 26. On that date the ankle jerks were absent and the plantar responses normal. On Feb. 28 there was an increase in tonus of the legs. The child had not been heard to speak at all, and she exhibited very little voluntary movement. Her breathing was shallow and accompanied by moans. There was an occasional sudden jerk, in which the eyes turned upwards. On March 12 she was still fretful, and still exhibited the biting reflex. Cardiac irregularities were noted on June 26 , and she died on July 2, about nine months after the onset of her illness.

NeCROPSY EXAMINATION.-Except for pulmonary congestion, the significant findings were restricted to the central nervous system. The brain weighed $1,220 \mathrm{~g}$. The pia-arachnoid was intensely congested. When the brain was sectioned, the grey matter was thought to be pinker than usual, and there was an increase in the size and number of the visible cerebral vessels.

Microscopic Findings.-Perivascular infiltration by lymphocytes and plasma cells was found in almost all regions of the brain. It was relatively slight in the 
meninges, which were slightly fibrosed, but conspicuous in the cerebral cortex. A All cortical regions were affected, but the frontal more heavily than any other. The infiltration consisted of mainly lymphocytes around the larger vessels, and predominantly plasma cells around the precapillaries and capillaries. In this respect the histological picture resembled that commonly seen in general paresis (Fig. 1). The iron reaction was, however, negative throughout the brain, and no spirochætes were found. There was undoubtedly some diffuse loss of nerve cells in all cortical areas, particularly evident in the frontal lobe, but its degree was difficult to assess since the cyto-architecture, especially in the deeper layers, was often obscured by an increase of cellularity due to a proliferation of the microglia and macroglia in addition to the inflammatory cells described above. The proliferation of microglia was both diffuse and focal, the latter giving rise to glial nodules, which were found not only in the cortex but also in most other parts of the grey and white matter of the brain. These glial nodules were independent of the blood vessels but occasionally formed around degenerating nerve cells. The majority of nerve cells showed changes best described as Nissl's acute cell change, though in some the change was more severe, to the point of dissolution of nuclei and ghost-cell formation. No inclusion bodies were seen in cells of the cortex or elsewhere. A moderately increased amount of fat was present in the nerve cells as well as in the endothelial cells and adventitial histiocytes of many mediumsized blood vessels. Holzer preparations showed an increase of glial fibres, particularly in the marginal and deepest layers of the cortex.

Similar changes were found in the corpus striatum and the thalamus, while the globus pallidus was largely spared. Damage to the substantia nigra was fairly heavy, approaching in extent that often seen in chronic encephalitis. It appeared to be shrunken, and Holzer preparations showed moderately heavy astrocytic proliferation. The number of its nerve cells was reduced, and many of the remaining cells showed various stages of severe degeneration, having shed their melanin pigment which was to be seen in hyperplastic microglial and adventitial cells in the vicinity. The inflammatory changes and microglial nodules were not conspicuous in the substantia nigra, but were found to an appreciable degree elsewhere in the midbrain and in the pons. They were mild in the medulla and cerebellum. The spinal cord showed no inflammatory changes, but there was some demyelination and increase of glia in the pyramidal tracts thought to be secondary to the cerebral changes.

A noteworthy feature of the case was the widespread diffuse glial proliferation throughout the cerebral white matter. For the most part this glial fibrosis was associated with very little alteration in the myelin or in the axis cylinders (Fig. 4), but in the centrum semi-ovale and the internal capsule it was associated with patchy demyelination. The demyelinated areas (Fig. 2) were irregular in outline, often poorly demarcated from the surrounding tissue, and shown by Nissl's stain to be cellular astrocytic scars (Fig. 3). In these areas the perivascular infiltration was most intense, and isolated plasma cells were noted in the parenchyma. The axis cylinders were reduced in number and were irregularly swollen and vacuolated and frequently fragmented. Glial fibrosis without demyelination was distributed in a patchy fashion throughout the brain stem, especially in perivascular areas and in the region of the olives and the nuclei of the pons.

\section{Discussion of CASE 1}

The finding meriting special emphasis is the widespread sclerosis of the white matter, revealed most characteristically 'in the sections stained by Holzer's technique and associated with irregular patches of demyelination in the most densely involved areas. Patches of demyelination have been found frequently as pathological residuals of an encephalitic process, and the German literature contains several reports of cases in which the demyelinated patches were thought to be indistinguishable from the plaques of multiple sclerosis* (Kufs, 1923 ; Bill, 1922 ; Peters, 1935). In our case the demyelinated areas were too irregular in outline and too poorly demarcated from the surrounding tissue to be taken for typical multiple sclerosis lesions. Globus (1937) has reported a case of encephalitis having an acute onset, running a course of three years, and developing such extensive scar formation in the midbrain as to cause clinical symptoms simulating braif tumour.

The cases in the literature most closely resembling ours are those reported by Scholz (1923), Bodechte and Guttman (1932) (two cases), and van Bogær t (1945) (three cases). In all these patients the illness developed gradually, five of the six patients were children, and in all the illness ran a sub-acute or chronic course. In all the pathological findings were mild meningitis and widespread perivascular lymphocytic and plasma-cell infiltration, microglial nodule formation, and widespread fibrous gliosis of the white matter. Scholz considers his case to be one of chronic epidemic encephalitis. Bodechtel and Guttman, and van Bogært, attach considerable importance to the finding of sclerosis of the white matter. On the basis of the changes in the white matter, Bodechtel and Guttman dismiss the diagnosis of encephalitis and classify their cases as diffuse sclerosis. Van Bogært specifically separates his cases from the primary demyelinating $ᄋ$ diseases, favours the possibility that they may be $D$ cases of encephalitis, and classifies them as "sub- 을. acute sclerosing leuco-encephalitis." Van Bogært's stand in this matter seems entirely reasonable and $\sigma$ only has the shortcoming, which he mentions $N$

- It remains to be seen to what degree this problem will be influenced $\omega$ by the recent claim of Margulis and others (1946) to have identified the same virus in postvaccinal encephalitis and disseminated sclerosis. 
himself, that a new term having only morphological significance is introduced (or rather, an old term employed by Spielmeyer but given a somewhat more precise meaning). It seems to the present writer that nothing is gained by classifying such cases as these with the demyelinating diseases. Whatever the final ætiological classification may prove to be, the present case confirms the reality of van Bogært's clinico-pathological concept.

Unfortunately, the serological studies of the spinal fluid are not complete, but neither the clinical course of the illness nor the pathological findings suggest a diagnosis of paresis.

\section{CASE 2}

A man, aged 30 years, was admitted to Cane Hill Hospital, Coulsdon, Surrey, on Oct. 16, 1941, and died on Jan. 5, 1945.

History BeFORE ADMiSSION.-Since this patient's illness was discovered shortly after he had enlisted in the Army, the question of compensation and service-connected disability arose, so that the history prior to June, 1940, may be inaccurate. He stated that he was well until 1930 , when he had some febrile illness with drowsiness. Thereafter he had attacks of double vision and impaired usefulness of his left leg. His wife insisted that he was entirely well until he joined the Army.

He was conscripted in June, 1940, and was discharged as medically unfit in December, 1940. During this time he complained of headaches, attacks of double vision and blindness, and of drowsiness. Under observation before discharge from the Service, he was described as rather childish and euphoric. He was dirty in his habits, boastful, and a pilferer. He had marked dysarthia. His pupils were small, equal, and slightly irregular, and they reacted sluggishly to light. The abdominal reflexes were absent. There was weakness of the left leg, and the left knee jerk was hyperactive. The plantar responses were normal. There was some inco-ordination in the heel-to-knee test. Slight coarse nystagmus and diplopia occurred on looking to the left. Spinal puncture revealed 8 cells per c.mm., a negative Wassermann reaction, $50 \mathrm{mg}$. of protein per $100 \mathrm{c} . \mathrm{cm}$., and a normal colloidal gold curve. The diagnosis at the time of discharge from the Service was "post-encephalitic syndrome."

From Dec. 31, 1940, until Oct. 16, 1941, he lived at home. He occasionally committed senseless and illplanned thefts, such as riding away on another person's motor-bike.

History After Admission.-At the time of admission to Cane Hill Hospital he was described as euphoric and poor in judgement. He regarded his ill-health as a joke. $\mathrm{He}$ had a poor memory, had difficulty in performing simple arithmetic, and expressed the grandiose idea that he was a personal friend of Sir Archibald Sinclair. His speech was slow and deliberate. He was slightly ataxic and was clumsy in the use of his fingers.

The Wassermann reactions of the blood and spinal fluid were negative. The spinal fluid protein was $80 \mathrm{mg}$. per $100 \mathrm{c.cm}$. The colloidal gold curve was 0122210000 . Spinal fluid examination repeated in November, 1942, and in January, 1944, showed the Wassermann reaction negative both times. In 1942 there were 8 cells per c.mm., the total protein was $80 \mathrm{mg} . \%$, and the gold curve was 1122321100 . In 1944 the cell count was 7 , and the total protein $50 \mathrm{mg} . \%$.

In the three years following his admission to the hospital, the patient's symptoms progressed very slowly. He remained euphoric and hoarded all manner of rubbish. In November, 1942, his general physical condition was good and very little change in his neurological status was noted except that his gait was now definitely ataxic. There was slight inco-ordination in the finger-to-nose test on the left, and the plantar responses were extensor on both sides. By November, 1943, he had a spastic gait and had lost sphincter control. On Jan. 3, 1945, he was found in a state of stupor, unable to walk or talk. His temperature was $98.6^{\circ} \mathrm{F}$. During the next two days he had a few epileptiform fits. He died on Jan. 5 without having regained consciousness. The final clinical diagnosis was disseminated sclerosis.

NeCropsy EXAMINATION.--Significant necropsy findings were restricted to the brain. The spinal cord was not available for examination. The brain weighed $1,410 \mathrm{~g}$. Both lateral ventricles, the third ventricle, and the optic recess were enlarged; the aqueduct and the fourth ventricle were normal ; the corpus striatum had a brownish colour; the substantia nigra was macroscopically normal in appearance.

MicrosCoPIC FINDINGS.-Many of the findings were identical with those in Case 1. There were, however, some significant differences.

The leptomeninges, throughout, were diffusely infiltrated with lymphocytes and plasma cells (Fig. 5), most intensely at the base of the brain in the region of the hypothalamus and optic chiasma. In the brain itself the perivascular lymphocytic and plasma cell infiltration was ubiquitous and heavy. In order of intensity, the hypothalamus (Fig. 6) and brain-stem came first, followed by the basal ganglia and then the cerebral cortex. The hippocampal region was very heavily involved, except in Ammon's horn, which was relatively lightly affected. There was also inflammatory change in the substantia nigra, but not more than in any other sub-cortical centre and without any appreciable degree of degeneration or loss of the melanin-containing pigment cells.

The inflammatory process was not confined to the grey matter, but occurred to an approximately equal degree in the white.

Microglial and macroglial proliferation was widespread. Glial nodules made up of microglial cells and astrocytes (Fig. 8) were encountered everywhere. In the centre of the nodules, nuclear debris derived from degenerating nerve cells was encountered often. Diffuse microglial and macroglial proliferation was ubiquitous, but occurred with particular intensity in the hypothalamus, chiasma and optic tract, corpora quadrigemina, the most medial portion of the cerebral peduncles, and the vicinity of the inferior olives. These areas of marked increase in cellularity were associated 
with intense vascular engorgement, small hæmorrhages, and severe nerve cell changes. The number of blood vessels was especially increased in the hypothalamus, optic chiasma (Fig. 7), and the medial and inferior portions of the temporal lobe. The adventitia of the walls of many of the vessels was proliferated, and the media had a hyaline appearance.

A less intense diffuse gliosis, demonstrable in silver carbonate and Holzer preparations, was found in the marginal layer of the cortex, areas around the ventricles, the subcortical white matter, and the corpus callosum. The gliosis in the cerebral white matter was not comparable in intensity with that described in the previous case.

In all sections examined, degenerative nerve cell changes were encountered. In the cortex this was most marked in the deeper layers. Nowhere, however, was the cortical architecture very markedly distorted. Nerve cell degeneration was most intense where the inflammatory changes were marked, but was also prominent in the dentate nuclei and the Purkinje cell layer, although the inflammatory changes in the cerebellum in general were mild. Many of the diseased nerve cells were shrunken and pyknotic and had tortuous processes. Others stained very poorly and were vacuolated, and there were small foci where nerve cells had dropped out altogether or were represented only by shadow cells. Fat stains revealed excessive neutral fat droplets in the majority of the nerve cells and in the walls of many or the medium-sized vessels.

The iron reaction was strongly positive in most of the sections examined, especially in sections from the cortex and hypothalamus. Iron was found in the walls of many of the small and medium-sized vessels and in microglial cells in the neighbourhood of such vessels (Fig. 9). No spirochætes were discovered.

Demyelination was encountered only in the hypothalamus and optic chiasma, where the inflammatory changes were most severe. The demyelination was slight in comparison with the severity of the inflammatory reaction and gliosis, and occurred in poorly demarcated, small patches.

\section{Discussion of CASE 2}

From the clinical and laboratory findings the diagnosis of disseminated sclerosis would appear to have been a logical one, but the pathological findings reveal no evidence for it whatsoever. The findings are almost exclusively inflammatory, and it does not seem reasonable to entertain any diagnostic possibility other than some form of encephalitis. General paresis must naturally be considered first because of the course of the illness and the positive iron reaction in many of the cerebral blood vessels. Examination of the spinal fluid on four different occasions over a period of four years always revealed the Wassermann reaction to be negative. The colloidal gold curve, which early in the illness was normal, in the course of time gradually assumed a low mid-zone character, but $\bar{Z}$ was never typical of paresis. Consistently negative $: \frac{\mathbb{C}}{C}$ serological findings such as these are almost never 0 encountered in untreated paresis (Stokes, 1944). Although the iron reaction is very highly character- 0 istic of paresis it has been described in other forms. (N) of encephalitis and therefore cannot be considered $\frac{9}{5}$ specific to paresis. Von Economo (1920) and Scholz (1923) mention pigment of hematogenous? origin in the glia cells and vessel walls of their cases $\vec{\Rightarrow}$ : of sub-chronic epidemic encephalitis, and Kingo. $(1934,1935)$ and Uchiyama (1925) noted that ${ }^{\circ}$ positive iron reactions occurred during and after $\overline{\bar{N}}$. Japanese B. type of encephalitis. In our case, also, $\frac{\bar{D}}{\widehat{\sigma}}$. the distribution of the inflammatory process was not $\stackrel{\mathbb{}}{\square}$ typical of paresis, in that the hypothalamus, brain stem, and optic nerve were more intensely involved $\vec{P}$ than the cortex, and that everywhere the white ${ }_{-}^{\circ}$ matter was involved almost as much as the grey. $\vec{\omega}$ For these reasons it is felt that paresis can be ruled out.

There is no pathological evidence of a tuberculous? process. The most reasonable diagnosis from the $\vec{O}$ pathological point of view would, therefore, appear to be one of the forms of virus encephalitis.

It is of interest that definite evidence of acute and $\mathrm{O}$ subacute or chronic lesions is to be found side by $\rightarrow$ side in the same areas, just as in many of the exampless of chronic encephalitis described in the literature. Thus, in the hypothalamus and the optic chiasmin $\overrightarrow{0}$ marked increase in vascularity with proliferatiog of the adventitia of the vessel walls and intense. fibrous gliosis were noted in the same microscopico field as very recent hæmorrhages.

\section{CASE 3}

A boy, aged nine years, was admitted to the Crichton Royal Hospital, Dumfries, on Nov. 12, 1943, and died $\overrightarrow{\bar{D}}$ on Jan. 23, 1944.

History Before ADMission.-In September, 1943, it was noted that the patient showed slight lapses of consciousness His head would fall on to his chest, his? hands would open once or twice, and for a second or? two he would appear to be completely unconscious. Heowould then carry on with what he had been doing, but? with a good deal of mental confusion. He would alsoo wake up suddenly in the night, blink vigorously, and, when questioned, appear to be in a state of alteredo consciousness. In the daytime he would occasionally fall to the floor in such an attack. From September, 1943, he became uncertain in his gait, staggering from side to side but more often to the left, and he seemed ton limp with his left foot.

In the next few weeks he became increasingly confused $N$ so that he could not be sent on the simplest errands and on occasion did not know the whereabouts of his home or of his own room. During October he became 


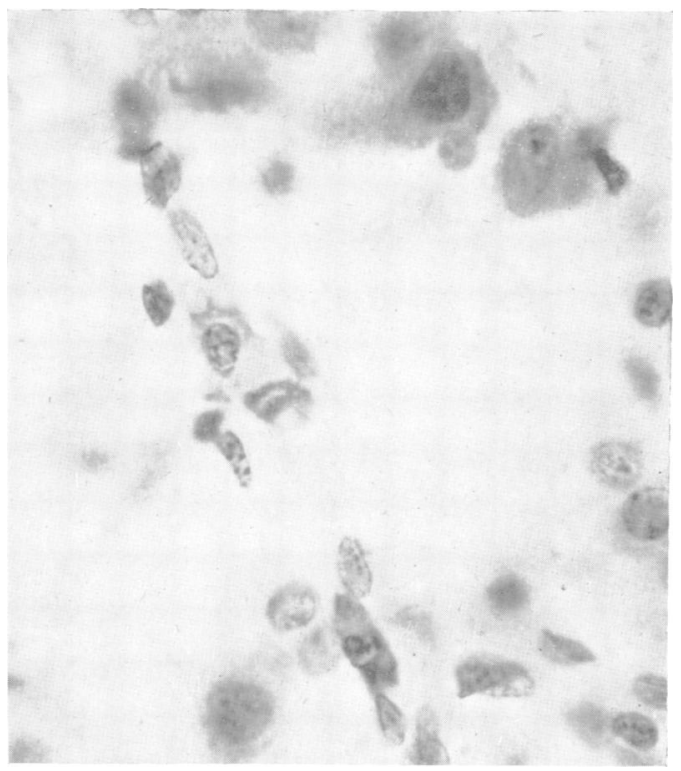

Fig. 1.-Case 1. Plasma cells around a small vessel in the frontal cortex. Nissl stain, $\times 850$.

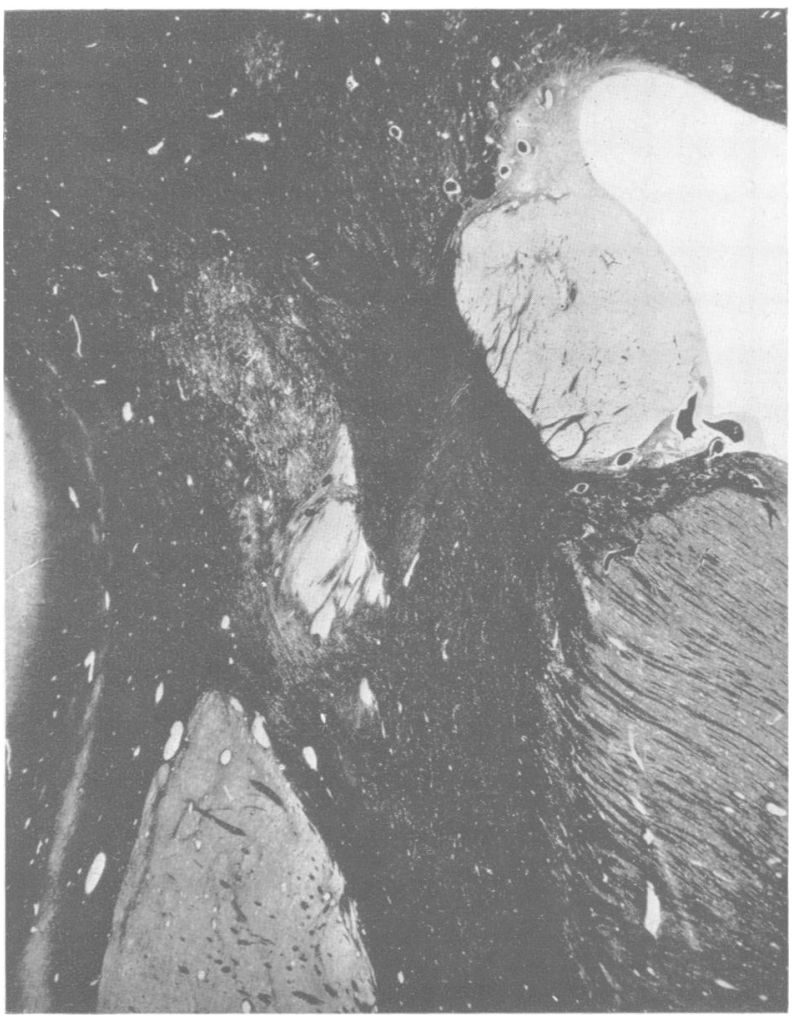

Fig. 2 (above).-Case 1. Poorly demarcated area of demyelination in the internal capsule. Heidenhain stain for myelin, $\rtimes 6$.

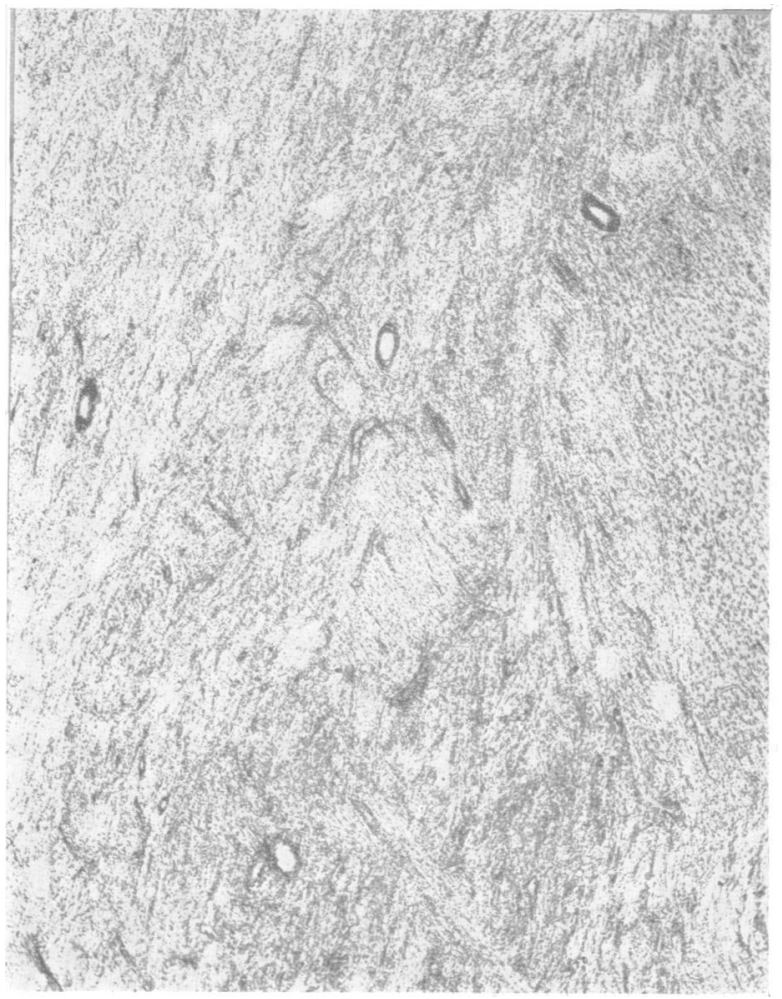

FIG. 3-Case 1. Nissl stain, higher magnification of demyelinated area shown in Fig. 2. Marked increase in cellularity and perivascular infiltration, $\times 27$. 


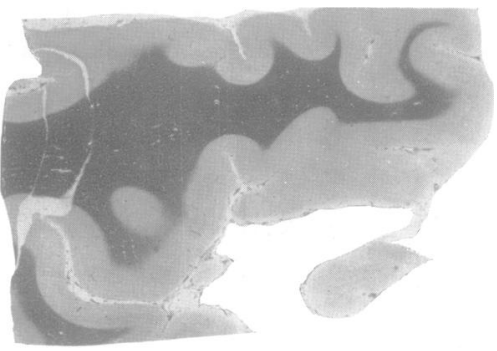

a)

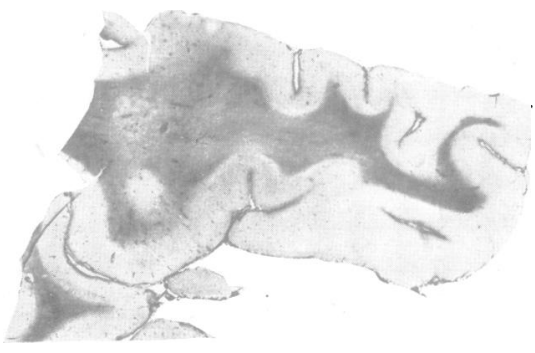

(b)

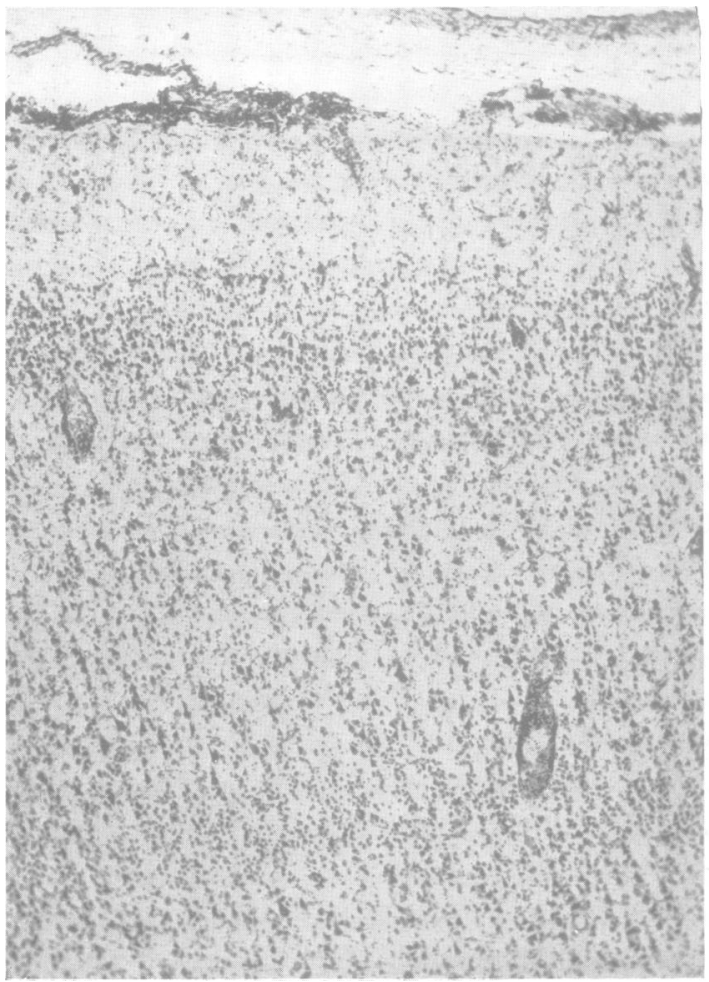

FIG. 4 (top left)-Case 1. (a) Heidenhain stain for myelin. (b) Holzer stain, showing glial fibrosis of the white matter with little demyelination, $\times 1 \cdot 4$.

Fig. 5 (lower left).-Case 2. Meningitis, increased cellularity of cortex, and infiltration around small blood vessels. Nissl stain, $\times 60$.

FIG. 6 (lower right).-Case 2. Marked increase in cellularity and perivascular infiltration in the hypothalamus. Nissl stain, $\times 60$.

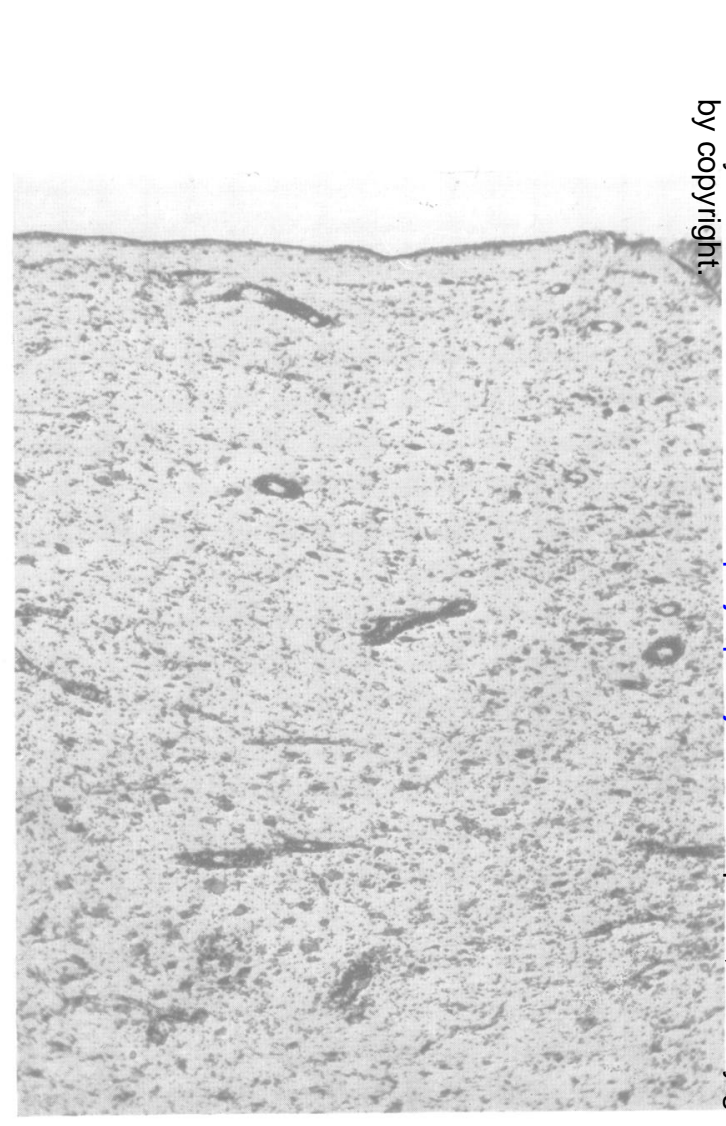




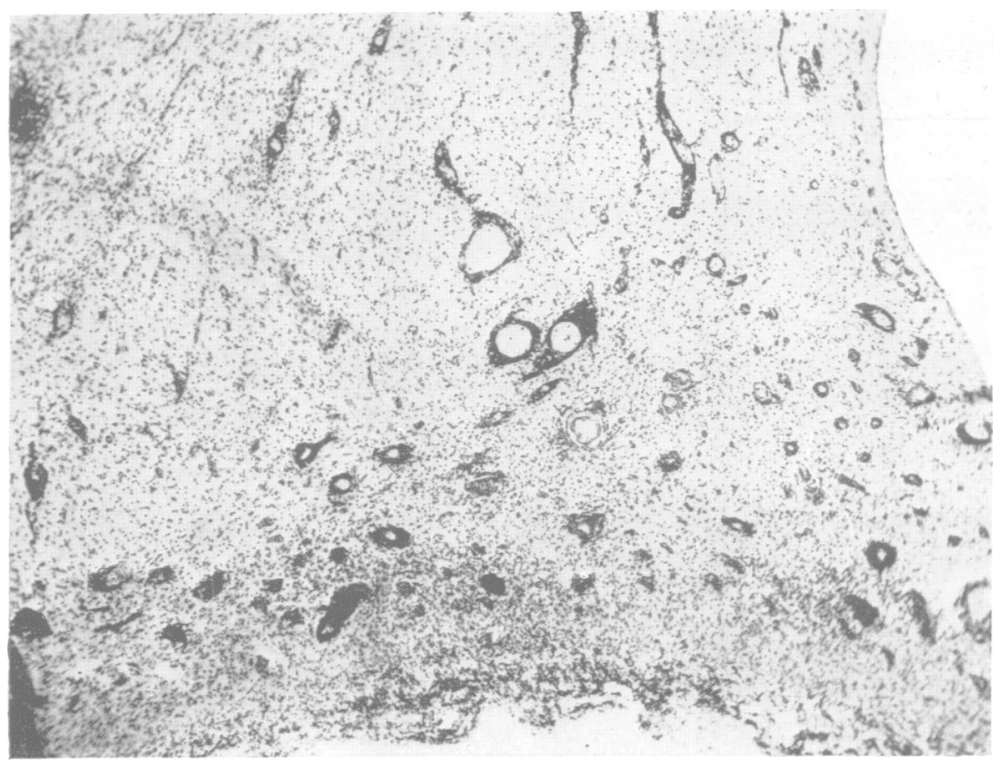

FIG. 7.-Case 2. Increased vascularity, increased cellularity, and perivascular infiltration in the optic chiasma. Nissl stain, $\times 55$.

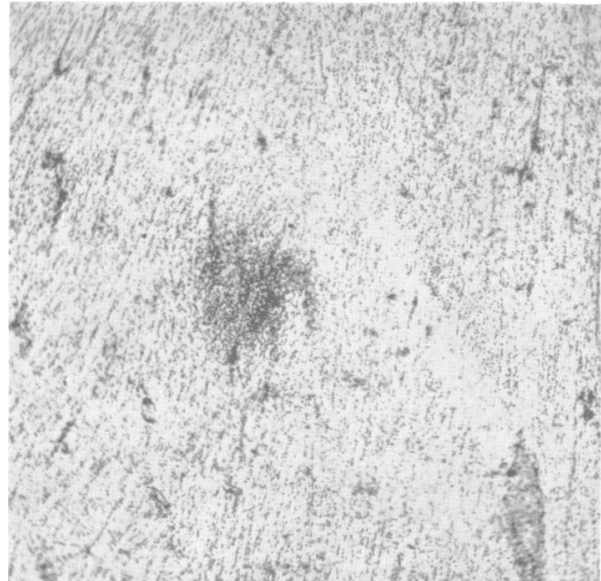

Fig. 8.-Case 2. Microglial nodule in the hypothalamus. Nissl stain, $\times 50$.

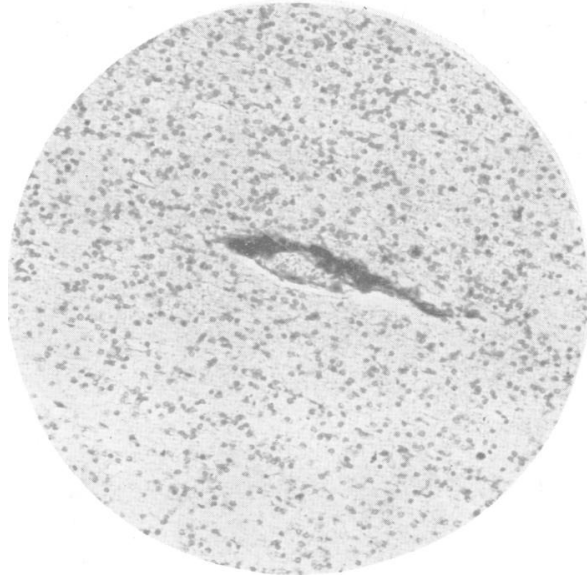

FIG. 9.-Case 2. Deposits of iron in the adventitial cells of the wall of a small vessel in the cerebrum. Turnbull's iron reaction, $\times 50$. 

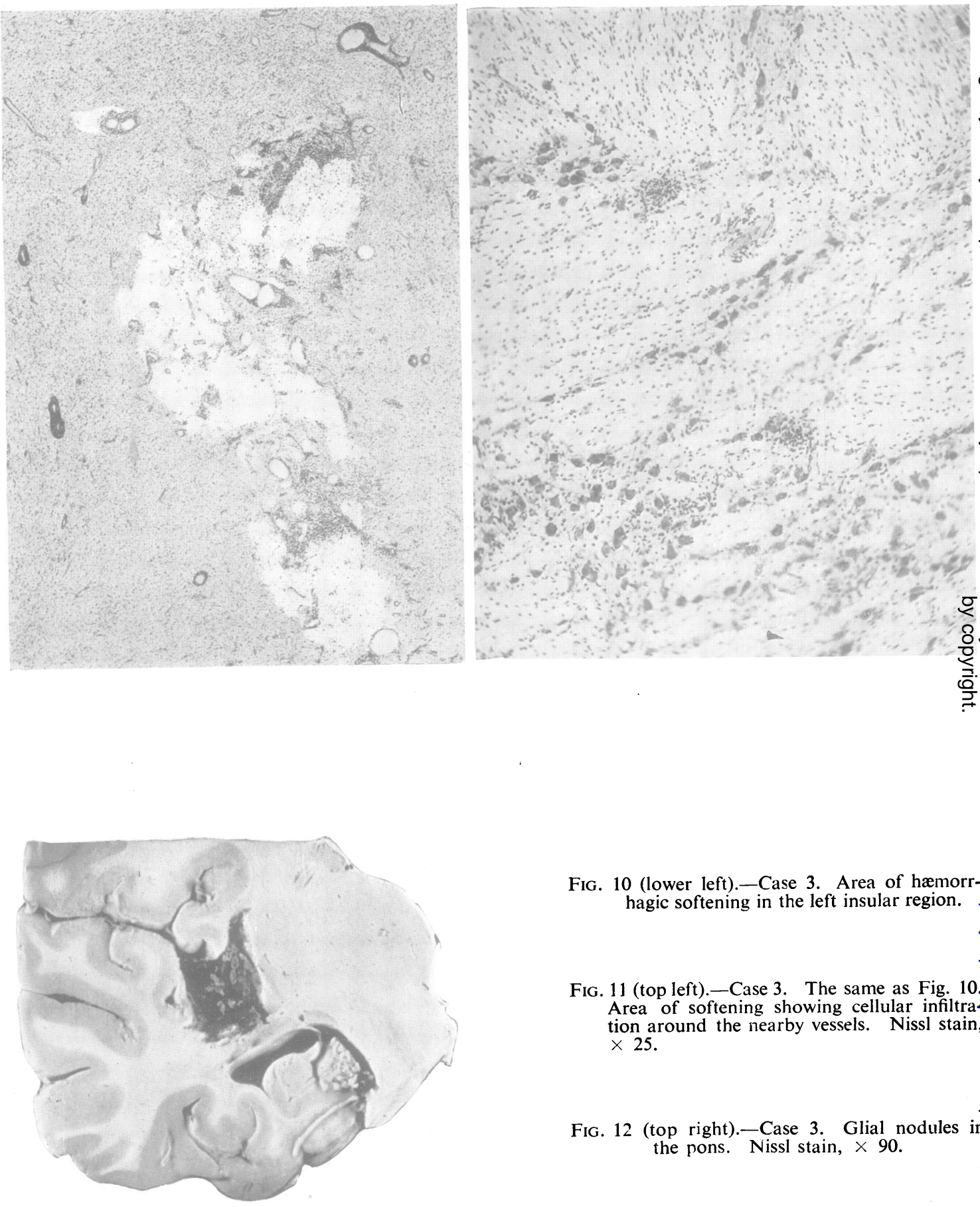

Fig. 10 (lower left).-Case 3. Area of hæmorrhagic softening in the left insular region.

FIG. 11 (top left).-Case 3. The same as Fig. 10.음 Area of softening showing cellular infiltra $\frac{3}{6}$. tion around the nearby vessels. Nissl stain, $\times 25$.

FIG. 12 (top right).-Case 3. Glial nodules in the pons. Nissl stain, $\times 90$. 
incontinent of urine, especially at night, and later became incontinent of fæces as well. He had been losing weight rapidly before admission to hospital.

The family and past histories were essentially irrelevant except that the patient had had asthma since the age of one year, not severe enough to keep him from school. One month before the onset of his present illness he had a particularly severe attack of asthma lasting several days.

ExAmINATION.-The patient exhibited a meaningless grin and his attention was difficult to maintain. There was poverty of spontaneous speech. The optic discs were normal but there was a pigmented patch in the left fundus. The pupils and ocular movements were normal. There was slight right facial weakness. Both arms displayed tremor on activity, and the left one also when at rest. Tonus was greater in the left arm than in the right. The right foot dragged in walking. The Babinski sign was positive on the right, but there was no significant difference in tendon reflexes on the two sides. The abdominal reflexes were normal. Marked apraxia in purposeful movements was observed.

LABORATORY STUDIES.-The Wassermann reactions of the blood and spinal fluid were negative. The spinal fluid pressure was $200 \mathrm{~mm}$. of water, there were three lymphocytes per c.mm., the chlorides were $750 \mathrm{mg} . \%$ and the total protein $45 \mathrm{mg} . \%$. The colloidal gold curve was 5543210000 . These spinal fluid findings were confirmed by subsequent examination. Guinea-pig inoculation with spinal fluid failed to reveal evidence of tuberculosis.

Electro-encephalography showed widespread dysrhythmia, with delta waves and short bursts of fast waves. An air encephalogram was negative. Biopsy from the left frontal region failed to support the possibility of a diagnosis of toxoplasmic encephalitis.

Course.-The patient went steadily downhill and died on Jan. 23, 1944.

NECROPSY EXAMINATION.-The significant necropsy findings were restricted to the brain. The spinal cord was not available for examination. The brain was markedly congested. There was moderate symmetrical enlargement of all the ventricles. A hæmmorhagic area the size of a bean was noted in the left insular region destroying part of the insula, claustrum, and putamen (Fig. 10). A few smaller areas of the same type were seen near the meninges in the occipital area.

Microscopically the lesions included small areas of cyst formation and necrosis, cellular infiltration in the meninges and around the blood vessels of the parenchyma, diffuse and focal glial hyperplasia, and extensive nerve cell degeneration.

The hæmorrhagic areas involving the insular and occipital regions were found to be areas of necrosis with cyst formation (Fig. 11). The cysts were filled with pigment-laden compound granular corpuscles and surrounded by a dense ring of astrocytic proliferation. In short, these areas had the appearance of hæmorrhagic infarcts. In the areas around the cysts inflammatory changes were very marked. There was intense infiltration of the blood vessel walls and perivascular spaces with lymphocytes and plasma cells. Myelin and Bielschowsky stains revealed the myelin sheaths and axis cylinders to have undergone extensive degeneration in these areas and to be largely replaced by glial fibres.

Although the occurrence of these cysts was limited to two areas in the cerebrum, the inflammatory changes were found in all sections examined. Thus there was a diffuse, mild lymphocytic and plasma cell meningitis. In the substance of the brain perivascular exudation of these cell types was widespread and included the smallest vessels, the walls of which were frequently plastered with plasma cells. Tiny microglial nodules were numerous throughout the cerebral cortex, basal ganglia, and brain stem (Fig. 12). These glial nodules frequently occurred around blood vessels and often contained a few plasma cells. The grey and white matter both contained these nodules and were about equally involved in the perivascular infiltration.

Except for the regions in the neighbourhood of the cysts described above, extensive demyelination was not encountered. There was some demyelination around a few of the small blood vessels in the white matter, and in these areas there was also slight microglial proliferation. The white matter everywhere had a vacuolated appearance thought to be due to œdema. Ependymal granulations were noted in the aqueduct.

In general the lesions were less severe below the thalamus than above, and the striatum was involved less than the thalamus. The hypothalamus was extensively affected. The cerebellum was involved least of all, except for the region of the dentate nucleus which manifested all the inflammatory changes described. Outside the cystic areas in the cerebrum degenerative nerve cell changes mostly of the acute type were rather uniformly distributed and were encountered at all levels. Inclusion bodies were not found. The iron reaction was negative throughout. Spirochætes were not discovered.

\section{Discussion of CASE 3}

The most interesting feature of this case from the pathological standpoint was the occurrence of the hæmorrhagic areas, having the appearance of infarcts, in the cerebrum. Von Economo specifically states that such lesions do not occur in epidemic encephalitis. He believed that the infection involved the nerve cells primarily, and that individual nerve cells frequently underwent necrosis but that large necrotic areas did not occur. He considered the glial proliferation and perivascular infiltration to be secondary to the primary disease process, viz., nerve cell degeneration. On the other hand, microscopic areas of necrosis have been described as characteristic of the acute stage of the western equine variety of encephalitis (Noran and Baker, 1943, 1944, 1945; Weil and Breslich, 1942), the eastern equine variety (Wesselhœft and others, 1938 ; Farber and others, 1940), the St. Louis type (Weil, 1934), the Japanese type (Uchiyama, 1925), 
and of encephalitis complicating herpes (Hassin and Rabens, 1944). Noran and Baker have described the pathological changes in one case of subacute (10 weeks' duration) encephalitis of the western equine type (1945), and in three cases dying years after the onset of the illness $(1943,1944,1945)$. In all these cases hypertrophic vascular lesions with narrowing and occlusion of the lumen and extensive replacement of the brain by cyst formation was encountered. They believe that in the western equine variety of encephalitis the virus attacks the blood vessels primarily, and that the other findings are secondary to the vascular lesions. In our case there were no severe lesions of the blood vessels other than the perivascular infiltrations.

In considering the resemblance of the lesions in this case to some of the extra-European types of epidemic encephalitis, it is of interest to note that none of the latter has ever been identified in Great Britain, and that so far as is known the encephalitis of von Economo is the only epidemic type that has occurred here (Brain and others, 1943 ; Editorial in the British Medical Journal, 1946).

The case in the literature most closely resembling our Case 3 is one described by Levy (1937). His patient was a child of 10 , whose illness had its onset with convulsions, and a duration of seven months. There were grossly visible hæmorrhagic lesions which microscopically were large areas of severe necrosis. At the margin of these necrotic areas and in the macroscopically normal regions there was extensive infiltration of the vessel walls and adventitial spaces with lymphocytes; there was diffuse glial proliferation, and a mild meningitis. Because of the lymphocytic infiltration of the vessel walls and the apparently vascular nature of the gross lesions, Levy considered his case to be a type of angiitis. He noted that veins and arteries were. about equally involved and that outside the necrotic areas there was neither necrosis of the vessel walls nor serious encroachment on the lumen. It is possible that the necrotic lesions in Levy's case as well as in ours represent a stage in the development of the cystic lesions shown by Noran and Baker to be characteristic of chronic Western equine encephalitis.

\section{General Comment}

Several points requiring special emphasis are raised by these three cases. The first concerns the question of the persistence of the virus of encephalitis in the central nervous system in an active form for long periods of time. Von Economo $(1920,1931)$ was convinced that this occurs, but the idea is by no means generally accepted (see discussion by Steven- son, 1942). According to von Economo's con- $\frac{\bar{O}}{Z}$ ception of epidemic encephalitis, in the majority of cases the virus is eliminated from the nervous system within a few weeks (possibly leaving a permanent sequel as a result of irreversible tissue $\widehat{a}$ damage), but in other cases the virus remains active $T$ and the infection runs an intermittent chronic course of a duration varying from months to years. He classifiéd his cases clinically as acute cases with $\underset{2}{\stackrel{0}{2}}$ protracted convalescence, sub-chronic and chronic. He used the term ' chronic encephalitis' to designate $\overrightarrow{\bar{\rho}}$ the well-known syndromes now more commonly referred to as post-encephalitic paralysis agitans, $\frac{\bar{O}}{\square}$ personality disorders of a psychopathic type, and $\overline{\frac{m}{2}}$ the like. His opinion that the virus frequently remains active was based on the slow development and frequently progressive nature of these disorders ${ }^{\infty}$ as well as the finding (subsequently noted by $\vec{\circ}$ many investigators) of active inflammatory and $\vec{\overrightarrow{ }}$ degenerative changes at autopsy on some of these $\stackrel{\omega}{\sigma}$ patients years after the onset of the acute illness (Meggendorfer, 1922 ; Hassin and Rotman, 1923 ;? McKinley, 1923 ; Hohman, 1925, Báhr, 1935). In $\vec{\circ}$ this respect the findings in our case support von i Economo's views, but naturally a final decision on 9 this difficult problem will only be reached by the $\overrightarrow{0}$ demonstration of the organisms in later stages of the disease process.

The second point of special interest concerns the ætiology of our cases. The distribution of the $\overrightarrow{0}$ inflammatory change was different from thet. generally regarded as characteristic of the chronic pathological residuals of lethargic encephalitis (Spatz, 1930 ; Stevenson, 1942). Most authors have found that in the latter the acute as well as the residual changes are most severe in the substantia nigra and in the grey matter around the posterior $\cong$ end of the third ventricle, the aqueduct, and the $\overrightarrow{0}$ upper end of the fourth ventricle. They are less severe in the globus pallidus, and usually negligible in the rest of the basal ganglia and the cerebral cortex. In Case 1 only the lesion of the substantia nigra approximated to that seen in the chronic form? of lethargic encephalitis, but this case was atypical $\frac{5}{3}$ because of the heavy involvement of the cerebral cortex and, in particular, of the cerebral white matter, $\delta$ which brings it into the type of leuco-encephalitis recently described by van Bogært (1945). The wide 을 distribution of the inflammatory change in all our $D$ cases resembles encephalitis of the equine, St. Louis, Japanese, and herpetic varieties more than N the von Economo type. Case 3, with its combination of diffuse and focal changes comes particularly $N$ close to the description of extra-European epidemic $\omega$ encephalitis (Uchiyama, 1925 ; Weil, 1934 ; Farber 
and others, 1940 ; Noran and Baker, 1943 ; Hassin and Rabens, 1944). These varieties of encephalitis have not yet been reported in Great Britain. It is interesting that Noran and Baker have found that the Western equine type occurs in a chronic form. This has not yet been shown for the other types mentioned. Analysis of individual cases on a clinical and morphological basis, as has been done in this paper, cannot be expected to settle the problem of ætiology, a problem that can only be solved by attempting to identify the ætiological agent, by actually isolating it from the brains of patients dying of encephalitis, or by demonstrating the presence of specific neutralizing antibodies.

In 1933, Dawson described a case of encephalitis occurring in a child, and running a course of several months, in which intranuclear inclusion bodies were found. A similar case was later described by Akelaitis and Zeldis (1942). Two such cases have been reported in Great Britain (Brain and others, 1943). All cases so far described have occurred in children and have run a subacute course of two to six months. My Cases 1 and 3 correspond to this description, but such a diagnosis is ruled out by the absence of inclusion bodies.

Finally, we must mention again that, although a positive iron reaction is certainly more characteristic of paresis than of any other condition (for example, see Jahnel, 1930 ; Galbraith, 1938) our Case 2 supports the statements of Kingo (1934), Uchiyama (1925), Scholz (1923) and von Economo (1920), that it may be encountered in other inflammatory diseases.

\section{Summary}

Three cases of encephalitis are described. All were insidious in onset and progressive in course over periods of time varying from four months to five years. Pathologically they were characterized by intense inflammatory changes widely distributed throughout the brain. The possible ætiology is discussed in each case. Case 1 was distinguished by a particularly severe involvement of the cerebral white matter which closely resembles the "leucoencephalite sclerosante subaigue" of van Bogært. The second case had a positive iron reaction. In the third there was the combination of diffuse and focal cystic lesions characteristic of some of the extra-European types of epidemic encephalitis.

My thanks are due to the Superintendents of the Crighton Royal Hospital, Dumfries, the Leavesden Hospital, Hertfordshire, and Cane Hill Hospital, Coulsdon, Surrey, for the clinical data of these cases. I am grateful to the London County Council for permission to work in the teaching and research laboratory of the Maudsley Hospital, and to the staff of the Lab- oratory, particularly to Dr. Alfred Meyer who suggested this investigation and gave advice in the preparation of the paper. I am also grateful for helpful criticism offered by Dr. J. G. Greenfield.

\section{REFERENCES}

Akelaitis, A. J., and Zeldis, L. J. (1942). Arch. Neurol. Psychiat., Chicago, 47, 353.

Bahr, M. A. (1935). J. nerv. ment. Dis., 82, 514.

Baker, A. B., and Noran, H. H. (1942). Arch. Neurol. Psychiat., Chicago, 47, 565.

Bill, E. (1922). Dtsch. Z. Nervenheilk., 73, 261.

Bodechtel, G., and Guttman, E. (1932). Z. Ges. Neurol. Psychiat., 138, 544.

Bogært, L. van (1945). J. Neurol. Neurosurg. Psychiat., 8, 101.

Brain, R., Greenfield, J. G., and Russell, D. (1943). Proc. roy. Soc. Med., 36, 319.

Dawson, J. R. (1933). Amer. J. Path., 9, 7.

Economo, C. von (1920). Wien. Arch. Inn. Med., 1, 371. (1931). "Encephalitis Lethargica, its Sequelæ and Treatment." London.

Editorial (1946). Brit. med. J., 1, 613.

Farber, S., Hill, A., Connerly, M. L., and Dingle, J. H. (1940). J. Amer. med. Ass., 114, 1726.

Galbraith, A. J. (1938). Brit. J. Vener. Dis., 14, 197.

Globus, J. G. (1937). J. Mt. Sinai Hosp., 4, 337.

Hassin, G. B., and Rabens, I. A. (1944). J. Neuropath. exp. Neurol., 3, 355.

- , and Rotman, D. B. (1923). Arch. Neurol. Psychiat., Chicago, 9, 22.

Hohman. L. B. (1925). J. Amer. med. Ass., 84, 1489.

Jahnel, F. (1930). Handbuch der Geisteskrankheiten, 11, 417 .

Kingo, S. (1934). Fukuoka. Acta. med., 27, 142. - (1935). Ibid., 28 (2), 86.

Krumholz, S., and Luhan, J. A. (1945). Arch. Neurol. Psychiat., Chicago, 53, 59.

Kufs, H. (1923). Z. Ges. Neurol. Psychiat., 86, 619.

Levy, N. A. (1937). Arch. Neurol. Psychiat., Chicago, 38, 775 .

Margulis, M. S., Soloviev, V. D., and Shubladze, A. K. (1946). J. Neurol., Neurosurg., Psychiat., 9, 63.

McCordock, N. A., Collier, W., and Gray, S. H. (1934). J. Amer. med. Ass., 103, 822.

McKinley, J. C. (1923). Arch. Neurol. Psychiat., Chicago, 9, 47.

Meggendorfer, F. (1922). Z. Ges. Neurol. Psychiat., $75,189$.

Noran, H. H., and Baker, A. B. (1943). Arch. Neurol. Psychiat., Chicago, 49, 398.

- (1944). Amer. J. Path., 20, 259.

- and. Baker, A. B. (1945). J. Neuropath. exp. Neurol., 4, 269.

Peters, G. (1935). Dtsch. Z. Nervenheilk., 138, 23.

Scholz, W. (1923). Z. Ges. Neurol. Psychiat., 86, 533.

Spatz, H. (1930). Handbuch der Geisteskrankheiten, 11, 157.

Stevenson, L. D. (1942). “Encephalitis, A Clinical Study." Edited by J. B. Neal. London.

Stokes, J. H. (1944). " Modern Clinical Syphilology." 3rd edit. Philadelphia.

Uchiyama, T. (1925). Jap. med. World, 5, 345.

Weil, A. (1934). Arch. Neurol. Psychiat., Chicago, 31, 1139.

_ _ , and Breslich, P. J. (1942). J. Neuropath. exp. Neurol., 1, 49.

Wesselhœft, C., Smith, E. C., and Branch, C. F., (1938).

J. Amer. med. Ass., 111, 1735. 